Int. J. Electrochem. Sci., 14 (2019) $7560-7569$

\title{
Covalent Functionalized Carbon Nanotube with Ionic Liquid and Its Application for Human Immunoglobulin G Immunosensor
}

\author{
Guangyu Shen*, Youming Shen \\ Hunan Province Cooperative Innovation Center for The Construction \& Development of Dongting \\ Lake Ecological Economic Zone, College of Chemistry and Material Engineering, Hunan University \\ of Arts and Science, Changde, 415000, PR China \\ *E-mail: sgyrab@163.com
}

doi: $10.20964 / 2019.08 .77$

Received: 16 April 2019 / Accepted: 31 May 2019 / Published: 30 June 2019

In this work, ionic liquid functionalized carbon nanotube was simply prepared via covalent bond between aldehyde-terminated ionic liquid and amino-terminated carbon nanotube. The combination overcame the shortages and shared the advantages of both ionic liquids and carbon nanotube. On the one hand, ionic liquid was prevented to leach out from electrode surface to electrolyte solution, which resulting a stable sensing interface. In the meantime, the degree of curling of CNT was decreased. On the other hand, this novel hybrid nanomaterial can further improve the conductivity of film modified on the electrode surface. The prepared immunosensor was used to detect human IgG in a linear range of 0.1$15 \mathrm{ng} \mathrm{mL}^{-1}$. The detection limit was $0.02 \mathrm{ng} \mathrm{mL}^{-1}(S / N=3)$. The electrochemical immunosensor with film fabricated with the hybrid nanomaterial had satisfactory reproducibility, high sensitivity, acceptable specificity and good stability.

Keywords: Ionic liquid; Covalent functionalized carbon nanotube; Chitosan; Electrochemical immunosensor

\section{FULL TEXT}

(C) 2019 The Authors. Published by ESG (www.electrochemsci.org). This article is an open access article distributed under the terms and conditions of the Creative Commons Attribution license (http://creativecommons.org/licenses/by/4.0/). 